\title{
Article \\ "Sexuality" through the Kaleidoscope: Sexual Orientation, Identity, and Behaviour in Asylum Claims in the United Kingdom
}

\begin{abstract}
Alex Powell (D)
School of Law, Faculty of Humanities and Social Sciences, Headington Campus, Oxford Brookes University, Oxford OX3 0BP, UK; a.powell@brookes.ac.uk

Abstract: The asylum system is a key site in which disputes over "sexuality" are contested. In refugee status determinations, administrative bodies are required to determine the actual or perceived sexuality of a claimant. This article draws on eight semi-structured interviews with refugees who claimed asylum in the United Kingdom based on their sexual diversity to deconstruct the distinct conceptions of sexual orientation, identity, and behaviour prevalent within the asylum system. It argues that the UK system overly privileges identity, falsely construing this as determinative of other aspects of sexuality. In doing so, it proposes a new framework of sexual diversity as a more relativist and inclusive way of making sense of sexual difference.
\end{abstract}

check for updates

Citation: Powell, Alex. 2021 "Sexuality" through the Kaleidoscope: Sexual Orientation, Identity, and Behaviour in Asylum Claims in the United Kingdom. Laws 10: 90. https: / / doi.org/10.3390/ laws 10040090

Received: 12 September 2021 Accepted: 15 November 2021 Published: 23 November 2021

Publisher's Note: MDPI stays neutral with regard to jurisdictional claims in published maps and institutional affiliations.

Copyright: (C) 2021 by the author. Licensee MDPI, Basel, Switzerland. This article is an open access article distributed under the terms and conditions of the Creative Commons Attribution (CC BY) license (https:/ / creativecommons.org/licenses/by/ $4.0 /)$.
Keywords: sexuality; queer theory; asylum; refugees; sexual orientation; sexual identity; sexual behaviour; sexual diversity; judicial review; Home Office; immigration

\section{Introduction}

In recent years, the treatment of sexually diverse refugees and asylum seekers has become an area of expanding interest for academic researchers (see for example: Bennett 2014; Giametta 2017, 2020; Khan 2016, 2019; Millbank 2009; Murray 2014; Powell 2020, 2021). Much of this interest has centered on the issues claimants face when attempting to prove that they are, or will be perceived as, a given "sexuality". While the existing research effectively and significantly draws attention to the credibility issues that arise in the context of asylum claims based on sexual minority status, this article seeks to present a critical interjection which questions the perceived unity (and utility) of the concept of "sexuality". Drawing on eight semi-structured interviews - undertaken between 2018 and 2020-the paper argues that sexuality has increasingly been collapsed into identity, with the result that the other two strands that were historically regarded as a part of the concept-behaviour and orientation-have come to be neglected. The result of this neglect is that, even as the words of UK asylum policy deny such an approach, only those asylum seekers presenting themselves in a manner that is consistent with a relatively circumscribed, and broadly "western", conception of sexuality are likely to be viewed as "genuine" (See also: Murray 2014).

Through offering a critical analysis of the 2016 Asylum Policy Instruction (hereafter: API), this paper seeks to look at the contemporary concept of "sexuality" through a kaleidoscope that draws attention to its incongruences with the lived realities of sexually diverse refugees. As such, the paper situates itself within a wider body of queer scholarship that attempts to render unfamiliar the assumptions, occlusions, and subjects of knowledge(s) associated with sexuality (Halberstam 1998, p. 13). In doing so, it poses critical questions regarding the embrace of identity politics, which has occurred within contemporary political and intellectual projects that aim to advance rights and protections for sexually diverse people (see also: Phelan 2000; Bernstein 2005; Adler 2018; Ashford et al. 2020; Powell 2021; Morris 2021a). 
The paper is organized into five sections. First, I discuss the contemporary swing towards identity politics within discourse and policy around sexuality. Although I do not claim this swing is new-indeed, Foucault (1998) relates the idea back to early sexology in the Victorian period-I suggest that many recent developments in the rights of sexually diverse people have been contingent on a conception of sexualities as pre-eminently identities. This has marginalized the orientational and behavioural ways in which sexual difference manifests. Second, I move to discuss the impact of identity politics within the asylum claims of sexually diverse people. I show that this reliance on identity is often implicit in the way in which the terms sexual orientation and sexual behaviour are deployed and understood. I then explain the methods utilized in conducting the interviews on which this study is based, before going on to discuss the narratives of the refugees I interviewed. Drawing on an ethnographically informed phenomenological narrative analysis approach, I show how participants rejected or contested the utility of identity as a way of making sense of their own sexual diversities (Black et al. 2011; Malagodi and Powell 2019; Powell 2021). They instead situated these diversities as being founded in forms of behaviour, desire, or as being irrelevant to their own self-conceptions. Finally, I consider the wider implications of these narratives for the way in which sexual diversity is commonly conceived in the UK. Thus, I suggest that these narratives demonstrate that the contemporary trend toward identity is epistemologically problematic and exclusionary of people who have been socialized outside of a "Western" context. Through doing this, I propose that greater conceptual space could be permitted by moving away from the deployment of sexuality and instead focusing on the idea of sexual diversity as a more inclusive and relativist knowledge framework through which to make sense of the heterogeneity of human sexual activities, desires, and labels.

This article contributes to longstanding debates regarding whether sexuality should be conceived of in queer/social constructivist or biological/identarian essentialist terms. The key original contribution of this article lies in providing empirical evidence to support the former. Specifically, I offer an appraisal of the 2016 API which, through drawing on the narratives of UK refugees who had their status granted on the basis of sexual diversity, exposes the conception of sexuality underlying that guidance as being one that does not correspond to the lived experiences of asylum claimants. The blending of queer theory and empirical evidence remains, with some notable exceptions, relatively rare (see for example: Morris 2021a; Powell 2021).

\section{Identity Politics: Sexuality as Sexual Identity}

The concept of sexuality brings together three constituent strands that can, despite notable interaction and cross-over, be interpreted as analytically distinct (Savin-Williams 2005, pp. 27-48; See also: Stychin 2014). Sexuality is comprised of (1) sexual orientation, which refers to the attractions one has to others; (2) sexual behaviour, which covers the intimate engagements in which a given person partakes; and (3) sexual identity, which covers a wider spectrum of social and political behaviours that demark who someone is. Often, asylum claims conflate these three concepts. For example, when the phrase sexual orientation is used to describe matters of identity (See for discussion: Powell 2020, pp. 150-51). Despite this, these three constituent concepts are often not in alignment. For example, some men who are sexually attracted to, and engage in sexual behaviour with, other men do not identify as gay or bisexual (Savin-Williams 2005, 2017). As this suggests, the constituent concepts that make up sexuality are often discordant. In this section, I will argue that sexuality has increasingly come to be viewed predominantly through the lens of identity.

Sexuality's status as biological fact or sociological construction has long been a topic of debate. Theorists operating across a diverse range of fields have engaged in a series of controversies over whether sexuality should be understood as a constructed category or an essentialist fact. A social constructivist understanding sees sexuality as one invented way of understanding disparate sexual, social, and emotional engagements (see for ex- 
ample: Foucault 1998; Weeks 2015). An essentialist understanding views sexuality as a biological fact that exists prior to socialization (see for example: Norton 2010). The essentialism/constructivism debate has been politically fraught terrain. One key reason for this is that, as Sullivan correctly identifies, the constructivist position, if adhered to in its pure form, would deprive sexuality of a fixed status to which key rights claims, and the rejection of moral condemnation, can be tethered (Sullivan 1995, pp. 56-69). For reasons advanced below, this paper adopts the constructivist position. Therefore, I begin from a premise that even while the sexual categories and languages we deploy to place people, and place ourselves, in a complex and diverse world, have become critical factors in shaping contemporary structures of sexuality and gender' (Weeks 2015, p. 1092), these categories are, fundamentally, social constructs. As such, we could construct new frameworks through which to make sense of these human experiences.

A connected, but not identical, debate has also raged about whether sexuality is a result of nature or nurture. It should be noted that one's position with regard to constructivism/essentialism cannot be assumed from one's stance on nature and nurture. This is because it is entirely consistent to argue that sexual orientation is a result of nature, that this is something genetically determined, and yet hold that the categories through which we understand that orientation are socially constructed and contingent. Put another way, one can hold that sexual orientation is genetically determined and still maintain that sexual identity (like all social labels) is a construct. As such, nothing in this article is intended, nor should be interpreted as suggesting, that sexual orientation is not biological. I am not, in what is written herein, seeking to contribute to the nature or nurture debate. Instead, my arguments are limited to the constructivist/essentialist discussion as summarized above.

Volume one of Foucault's (1998) The History of Sexuality set out how the Victorian period was a time in which social categories such as that of the "homosexual" came to be constructed as a way of making sense of sexual diversity. Those who had non-normative sexual desires or who participated in non-normative sexual activities were subjected to a series of logics where one's desires' and behaviours' transformed from what had historically been seen as aberrant behaviours (the act of sodomy) to a fundamental element of who one was (the homosexual person) (Foucault 1998). In this sense, the claim that one's sexual diversities were a form of identity, 'a sexuality', originates in the highly modernist, positivist, desire to categorize and label social phenomena (Morris 2021a). While this may initially have been used as a means through which to control and limit sexual freedom, these categories came to be utilized in demands for rights and respect by those to whom they were applied. The point here is that the categories through which sexual diversity became known 'did not aim to suppress it, but rather to give it an analytical, visible and permanent reality: it was implanted in bodies, slipped in beneath modes of conduct, made into a principle of classification and intelligibility, established as a raison d'être and a natural order of disorder' (Foucault 1998, p. 44). Thus, as Foucault's account above makes clear, the categories of sexuality are constructed to make sense of diverse sexualities not with the power of suppression or interdiction, but rather to provide a way of classifying people into groups. Ultimately, such classifications can serve both violent and liberatory ends. Indeed, sometimes both liberation and violence are served simultaneously.

Furthermore, as Morris notes, 'Sexualities scholarship has drawn on this observation to critique the essentialising tendency of not only traditional research methods, but also contemporary rights-based campaigns for sexual minorities' (Morris 2021a, p. 2). Thus, as Morris suggests, it has come to be the case that within the logics of LGBTQ+ activism and politics, identity has become a key vessel through which many demands for rights, protections, and inclusion are founded. Thus, "sexuality" comes to be viewed predominantly as an identity (see further: Powell 2020, pp. 156-57). This view of sexuality as predominantly an identity, in turn, becomes central to the platforms of law reform that are selected and enacted in addressing disparate and non-normative sexualities (Adler 2018). 
Norton, in a critique of Foucault and constructivist scholarship more generally, defined essentialism in the context of sexuality as the view that the " essence" or core of homosexual desire is innate, congenital, constitutional, stable and fixed rather than fluid' (Norton 2010, p. 7). Applying this, it can be seen that the construction of sexuality described by Foucault ultimately comes to generate the same fixed and fundamental status that essentialism describes, even if this is for different reasons. Indeed, as Rubin and Butler have argued, the scripts governing sexuality have been crafted over a long time and moving out of them can be a fraught process (Rubin and Butler 1994, pp. 69-70). Otherwise put, we have constructed categories of sexual diversity that are viewed as essentially fixed and which, given their hegemony, are difficult to think outside of.

Building on the ideas of Foucault, Adler has argued that the search for identity-based rights to protect people on the basis of their sexuality can be understood as a form of equal rights discourse (Adler 2018). She characterizes 'LGBT equal rights discourse' as being a series of common narratives around equality and inclusion that depict and frame sexual minorities in specific and limited terms (Adler 2018, p. 3). One of the core strands here is the idea that identity is something that we are born with (Johnston 2015; Powell 2020; See also: Phelan 2000). Johnston defines the "Born This Way" phenomenon as 'political and quasi-scientific claims that sexual orientation and gender identity are immutable and intrinsic facts' (Johnston 2015, p. 140). Thus, as opposed to simply arguing that sexual orientations (our attractions) are something that is innate or biologically determined, such arguments suggest that our sexuality is a part of "who" we are, that our identities are also something we are, essentially, born into. This further suggests that our very constitution as subjects is dependent upon our sexual identity. As such, narratives such as "Born This Way" construct a reality where sexuality is correlated with "truth", and where the act of "coming out" is viewed as a fundamental statement of a person's essential being (Foucault 1998; Sedgwick 2008).

At a more practical level, an example of the focus on identity can be taken from Stonewall's campaign slogan, 'some people are gay, get over it' (Stonewall 2007). This campaign demarcates being gay as marking one out as a particular kind of person. It therefore constitutes a position that logically entails a focus on identity. It seeks acceptance for a characteristic that is "fundamental" to who one is as a person. As such, it is argued that sexuality has increasingly become associated with a form of identity politics. Traditionally, identity politics has been depicted as being a liberal and left-wing standpoint or perspective (See: Bernstein 2005). However, as this article suggests, the utility of such a position for advancing the rights of sexually diverse people can be questioned. This is not to deny that sexuality, viewed through the lens of identity, has been a successful tactic for securing the protection of sexually diverse people within liberal societies (see: Hall 1994). In accordance with Spivak's concept of strategic essentialism-a concept according to which groups mobilize around shared characteristics and, in so doing, temporarily erase differences between those who hold those characteristics-identity politics has provided a fundamental strategy onto which many rights claims have been tethered (Spivak 1985, pp. 175-87). This has been pivotal to the acceptance of sexuality-based rights. Indeed, it has anchored claims to their fundamental nature.

In the refugee context, this has been productive because, as Hathaway has argued, when constructing a Particular Social Group, 'whatever the common characteristic that defines the group, it must be one that the members of the group cannot change or should not be required to change' (Hathaway 1998, p. 160). As such, conceptualizing sexuality as a pre-discursive identity has had the effect of constructing a stable category around which refugee status and other human rights claims can be anchored. Accordingly, arguing that sexuality as identity has not been a useful tactic would be simplistic. Instead, this article is a call to acknowledge there are trade-offs associated with the deployment of identity-at least when such identity is conceived in fixed terms-and that some of these trade-offs emerge within the asylum claims of sexually diverse people. 
To summarize this, I have argued that the rights of sexually diverse people are often contingent on a framework that conceptualizes sexuality as an identity, more specifically a fixed identity. This logic forms the corpus that Adler has identified as 'LGBT equal rights discourse'. The narrative of LGBT equal rights sets the terms of debate for many questions over sexual (and gender) diversity. This is to say that, LGBT equal rights discourse has constructed a grid of understanding (Foucault 1970), through which sexual diversity is made sense of. In other words, sexuality as identity is a narrow lens 'through which our understanding of the world is filtered' (Morris 2021b, p. 2). As such, it is difficult for narratives that do not correspond to this lens to be understood and interpreted. The lenses we construct limit the types of difference that are thinkable. As such, when asylum decision-makers are charged with determining whether someone is of a given sexuality, the lens through which they analyse such claims comes to be conditioned by our contemporary conceptions of sexuality as a fixed identity. Ahmed draws this out well in her engagement with the concept of sexual orientation through the lens of phenomenology. Specifically, she examines how "The concept of "orientations" allows us to expose how life gets directed in some ways rather than others, through the very requirement that we follow what is already given to us' (Ahmed 2006, p. 21). As such, Ahmed usefully sheds light on how particular orientations are the result of following certain life courses, rather than results of being attracted or drawn towards a given object (in this case another human of the same sex). Thus, building on Ahmed's work, we can see that decision-makers, when faced with sexual diversities, are likely to follow a familiar path. This means that they will seek identity performances that map onto the everyday and the ordinary. This is because lines of thought are, in a sense, performative. They 'depend on the repetition of norms and conventions, of routes and paths taken, but they are also created as an effect of this repetition' (Ahmed 2006, p. 16). Indeed, as Bruce-Jones has argued, the forms of sexual diversity commonly deployed within asylum decision-making themselves come back to (re)condition the expectations of decision-makers and their approaches to subsequent claims (Bruce-Jones 2015).

Turning towards the international context, it is pertinent to note that anti-colonial scholars such as Massad (2002) have called attention to the totalizing way in which "western" activists often seek to apply a sexuality considered as an identity to all cultures and contexts. In his work on The Gay International, Massad critiques LGBT human rights activists who advance protection claims premised on the assumption that:

Homosexuals, gays, and lesbians are universal categories that exist everywhere in the world and, based on this prediscursive axiom, the Gay International sets itself the mission of defending them by demanding that their rights as "homosexuals" be granted where they are denied and be respected where they are violated. (Massad 2002, p. 363)

As this suggests, even if identity is a strategically useful framework for thinking through sexual difference, this does not mean that it is a universalizable truth about the world. Rather, "sexuality" — essentialized into a form of identity—is just one way among many of making sense of sexual and gender difference. It is a way that may not be shared by people from different cultural backgrounds. Indeed, as Malagodi and I have argued elsewhere, some states have protected sexual diversities through different cultural frameworks such as the idea of third genders (Malagodi and Powell 2019; Powell and Malagodi 2021).

\section{3. "Sexuality" and Asylum Claims}

The above-mentioned issues of sexuality being viewed narrowly as an identity are drawn into sharp relief within administrative processes and systems that require decisionmakers to directly assess the "validity" of a claimant's sexual differences. An example of such a system is the asylum system. Since 1999, UK caselaw has established that sexually 
diverse people can claim asylum on the basis that they constitute a Particular Social Group. ${ }^{1}$ The idea of a Particular Social Group is derived from article 1A(2) of the Refugee convention which states that,

A person who owing to a well-founded fear of being persecuted for reasons of race, religion, nationality, membership of a particular social group or political opinion, is outside the country of his nationality and is unable, or owing to such fear, is unwilling to avail himself of the protection of that country; or who, not having a nationality and being outside the country of his former habitual residence as a result of such events, is unable or, owing to such fear, is unwilling to return to it. ${ }^{2}$

Thus, the general requirement for a sexually diverse person to qualify as a refugee is that they have a well-founded fear of persecution due to their membership of a Particular Social Group founded around their sexual diversity. For example, such a social group may be constructed around the identity of gay men. However, note should be taken that a Particular Social Group could also be formed around a more conduct-driven formation such as 'men who have sex with men' or 'women fleeing forced marriage'. Finally, because of this well-founded fear of persecution, the claimant must be unable or unwilling to return to their country of origin.

There is no international body that has enforceable powers to implement the refugee definition. However, the United Nations High Commissioner for Refugees does issue guidance on how the Convention should be interpreted and applied. ${ }^{3}$ The Convention clearly places an obligation on states to recognize as refugees all people who meet the above definition. As a result of this, while the processes through which refugee status is determined differ from state to state, they are generally regarded as being a process of recognition rather than decision.

The original text of the convention, written in the period after the second world war, clearly did not envisage that it would be used to protect those fleeing persecution that arose as a result of their sexual diversity. Indeed, as Honkala has argued, the convention has often been read in masculine terms that envisage the refugee as a person involved in public actions that would be conceived of as self-evidently political (Honkala 2017). Despite this, the Convention has expanded to keep pace with wider developments in the related field of human rights law (Hathaway 2005). As such, in the 1999 case of Shah and Islam, the court made an obiter finding that "homosexuals" could constitute a Particular Social Group for the purposes of the Convention. This was the start, rather than the end, of the struggle to ensure that sexually diverse people would be protected by the Convention. In the 1999 case, Jain, a practice known as "discretion reasoning" began to be applied both in the UK, and in other common law jurisdictions such as Australia and Canada. ${ }^{4}$ In one Australian case, discretion reasoning was described as a 'reasonable expectation that persons should, to the extent that it is possible, co-operate in their own protection'. ${ }^{5}$ The rationale behind this form of reasoning was, in essence, that claimants would not have a well-founded fear of persecution if they could avoid that persecution by keeping their sexuality a secret. ${ }^{6}$ During this period, discretion reasoning resulted in claims founded on sexual diversity facing a disproportionately high chance of rejection (Spijkerboer 2013; Hanna 2005). Dustin has argued that discretion effectively operated as a catch-all excuse for rejection, featuring a concerning amount of circular thinking (Dustin 2018, pp. 109-12). Therefore, discretion

\footnotetext{
Islam v Secretary of State for the Home Department and R v Immigration Appeals Tribunal Ex p Shah [1999] UKHL 20, [1999] 2 AC 629.

Convention Relating to the Status of Refugees, 28 July 1951, 189 UNTS 137, Art1A(2).

General Assembly Resolution 428 (v) of 14 December 1950, Statute of the Office of the United Nations High Commissioner for Refugees.

Jain v. Secretary of State for the Home Department [1999] EWCA Civ 3009.

V95/03567 [1996] RRTA 246. P. 246.

6 It is interesting to note here that, in an inversion of the over-privileging of identity I am outlining in this paper, the previous scenario saw on over-privileging of behaviour. With Chelvan arguing that 'The effect of Jain was that the court's understanding of the lives of gay men resulted in a purely "conduct-driven approach" reducing their lives to the engagement of the sexual act ... in the so-called "privacy" of the bedroom' (Chelvan 2011, p. 57).
} 
should be viewed as a key contributor to the startling $98 \%$ rejection rate for sexual diversity asylum claims recorded by Rainbow Migration ${ }^{7}$ prior to 2010 (UKLGIG 2013, p. 10).

In 2010, there was a fundamental change in the UK's approach to sexual diversity asylum claims. The judgement of the Supreme Court in the combined cases of HJ (Iran) and HT (Cameroon) $)^{8}$ ruled that discretion reasoning was incompatible with the Refugee Convention and introduced a new test to be applied in sexual minority asylum claims. ${ }^{9}$ The decision was initially celebrated by groups such as Rainbow Migration, who heralded it as a 'key factor in the improvement of first decisions' (UKLGIG 2013). However, others such as Chelvan (2011) and Millbank (2009) identified that such a change in the law would herald a shift from 'discretion to disbelief', placing a greater emphasis on requiring asylum seekers to "prove" their "sexualities". Giving weight to Rainbow Migration's finding that between 2011 and 2013, 86\% of rejected claims were refused due to a lack of credibility, these concerns seem to have been accurate (UKLGIG 2013, p. 12).

The reasons for this shift in the grounds on which claims were refused may well lie in the new test that HJ and HT introduced. The new test states that the decision-maker should first 'ask itself whether it is satisfied on the evidence that he [the claimant] is gay' [82]. If this first stage is satisfied, then the decision-maker should 'ask itself whether it is satisfied on the available evidence that gay people who lived openly would be liable to persecution in the applicant's country of nationality' [82]. If this is satisfied, then the third stage of the test calls for the decision-maker to 'Consider what the applicant would do if he were returned to that country' [82]. If the applicant would be open ${ }^{10}$ about their "sexuality", then they are a refugee. If the claimant would be discreet about their "sexuality" to avoid persecution, then they are a refugee. However, if the claimant would be discreet by choice, or to avoid causing upset or disappointment to their friends and family, then they are not a refugee.

The main issue with this test is that it sets proving one's sexual diversity as the first hurdle that an asylum seeker must pass, while simultaneously offering no guidance to decision-makers about how sexual minority status is to be identified. Thus, as Rachel Lewis aptly puts it, 'decision-makers still have no idea what claimants need to do to prove their sexual orientation' (Lewis 2014, p. 963). In the immediate aftermath of the HJ and $H T$ decision, the test appeared to set in motion a trend towards sexually explicit evidence (Juss 2015). However, such evidence was prohibited by the Court of Justice of the European Union in $C-148 / 13, C-149 / 13$ and $C-150 / 13$ (hereafter $A, B$, and $C$ ). ${ }^{11}$ The UK, at the time of $A, B$, and $C$, was a member state of the European Union and, as such, changed its asylum practice issuing new APIs in 2015 and further revising these in 2016. The 2016 API continues to be the most up-to-date Home Office policy on how to approach asylum claims by sexually diverse people. The $A, B$, and $C$ case sets out that evidence of a sexually explicit nature, or questions that focus overly on sexual practices, should not be permitted. The decision also makes clear that questions based on stereotypes should not be relied on as a sole basis of decision.

The 2016 API can be viewed as following the wider rhythm of LGBT equal rights discourse in heralding an embracement of identity politics. Indeed, Chelvan-whose Difference, Shame, Stigma Harm (Hereafter: DSSH) model was partially adopted by the Home Office within the 2016 API-characterized recent UK asylum policy as a part of a broader push to assess the credibility of "sexuality" in terms of identities rather than sexual practices (Chelvan 2011, pp. 60-62). Under both Chelvan's DSSH model, and the 2016 API, decision-makers are instructed to seek examples of "difference" as one means through which to determine whether the claimant is a sexually diverse person (Rumbach 2015;

\footnotetext{
Rainbow Migration were called the UK Lesbian and Gay Immigration (UKLGIG) group until 2021. This name is retained in their earlier reports. [2010] UKSC 31.

It should be noted that the courts have also confirmed that this test is of general application to other Particular Social Group asylum claims.

That is to say, if they would act in a way which made their sexual diversity apparent to others.

$1 \quad$ A, B and C v Staatssecretaris Van Veilighed en Justitie [2014] ECRI 2406.
} 
Chelvan 2020). For example, the API section entitled "Responding to Claimant's Narrative: Issues Around Difference" informs decision-makers that,

Most LGB asylum claimants live their lives in societies in which straight is considered the norm. From the perspective of the persecutor, the issue can be the fact that the individual is not conforming to common prevailing normative heterosexual stereotypes. In effect, the behaviour which may give rise to harm, harassment or persecution may not be LGB behaviour ... but behaviour or lifestyles which are deemed not be heterosexual enough. (UK Visas and Immigration 2016, p. 26)

While this section of the policy is careful to remind decision-makers that difference is a matter of non-conformity, the policy fails to account for the fact that decision-makers' conceptions of "difference" will be contingent on the lenses through which they make sense of the world. The policy further compounds this by offering examples of difference that directly correspond to the tropes common to sexual identity development in the UK context, stating that,

A wide variety of indicators may be presented in narratives by claimants, which may suggest a sense of being different or "apart from". Such indicators may include childhood behaviours indicating strong identification with the opposite gender, while for others experiences of difference may be manifested in unusual feelings and strong emotions towards another person of the same sex. (UK Visas and Immigration 2016, p. 27)

While the policy does note both that 'not every LGB person will have experience of or be able to communicate any sense of being different' and that 'caseworkers must have no expectations of any "common" themes to be presented' (UK Visas and Immigration 2016, p. 27), the stressing of difference leaves decision-makers with no guidance on how to address sexual diversities that do not figure as fundamental to the lives of claimants. As Dawson and Gerber further point out, such narratives of identity development are often not applicable to sexually diverse women (Dawson and Gerber 2017, p. 307).

The forms of evidence that decision-makers are encouraged to look for tend to relate more clearly to identity than they do to attractions or behaviours. While it could sustainably be argued that the issue here is stereotypes rather than identity per-se, the focus on identity is deepened within other elements of the policy that instruct decision-makers that 'any perceived lack of contact with the LGB community is a relevant area of investigation to explore' (UK Visas and Immigration 2016, p. 23). Unpacking this, it becomes clear that-despite the use of purportedly neutral terms such as difference-sexuality is being envisaged as an identity that correlates to certain cultural and social engagements. Indeed, Rainbow Migration, in their reports, have noted the same problematic over-reliance on the logics of identity. In their 2018, Still Falling Short, report they identified that,

UKLGIG has welcomed the focus on sexual identity rather than sexual practices in Home Office credibility assessments. This has been largely facilitated by examining a person's emotional development. With this important change, however, comes the need for critical reflection on a slightly different emerging issue. While apparently intended as non-prescriptive in the APIs, the Home Office use of this type of exploration has often resulted in swinging the pendulum away from sexual conduct to excessive focus on claimants being able to articulate sophisticated accounts of self-realisation (stories of recognizing one's identity), searching for evidence of a particular account of development of identity. (UKLGIG 2018, pp. 23-26)

As this suggests, some of the organizations working with sexually diverse people have increasingly noted the extent to which sexuality is being conceived of as an identity by those tasked with determining refugee status. 
It is recognized that the 2016 API is intended to be framed in non-prescriptive terms. This is made clear by the framing of each element of the policy as an example of the kinds of evidence and narratives that might help to establish the claim, rather than a list of what is needed. However, it is argued that, when the prescribed forms of evidence correspond to the familiar unspoken ways in which decision-makers will commonly apprehend sexuality (Ahmed 2006), what is originally intended as non-prescriptive list ultimately becomes calcified as a list of firm and fixed expectations around what a credible narrative is (Dawson and Gerber 2017).

This article highlights that there is a tension here in that the 2016 API, and the DSSH model it is partially based on, are intended to be progressive documents that guide decisionmakers as to how, in a post-discretion landscape, they might identify people who are genuinely in need of protection. ${ }^{12}$ Thus, undermining the idea that they correspond to the lived realities of claimants might legitimately be argued to be depriving asylum seekers and their advocates of a tool through which claims can be established. However, it should be recognized that there are limits to how progressive these policies can be, given that they work to cement particular conceptions of sexual difference that may not, as I explore in the second half of this article, correspond to the lived realities of sexually diverse refugees and asylum seekers. Indeed, where these conceptions do not correspond to the lived realities of asylum seekers, they may provide reasons for rejection, rather than assisting claimants in putting forward their case.

The API should also be considered in the context of the wider guidance issued to decision-makers. For example, while the API offers clear guidance on how to approach issues relating to sexuality/sexual diversity based claims, it should also be noted that decision-makers are required to comply with the 2015 API Assessing Credibility and Refugee Status, which states, inter-alia, that

The claimant's testimony and other evidence should be consistent with information (COI) about events in the country of persecution and with any other available information or expert evidence ... the greater the correlation between aspects of the account and external evidence, the greater weight caseworkers should attribute to those aspects. (UK Visas and Immigration 2015, p. 15)

Given the limitations of Country Information regarding sexual minorities, this can often mean that such claims are viewed as not being supported by external credibility, or, as Bruce-Jones has argued, that claimants end up essentially being assessed on the extent to which their sexuality/sexual diversity corresponds to the judge or decision-makers own conceptions of sexual identity (Bruce-Jones 2015, p. 114).

The second half of this article explores how the sexually diverse refugees I spoke to understand their own sexual orientations, behaviors, and identities. I begin by briefly outlining the methods used during both the interview and analysis stages of the research. I then place the participants' narratives in conversation with sections of the 2016 API with a view to identifying areas of mismatch between the self-conceptions of the refugees and the conceptions of sexuality underlying the API.

\section{Methodology}

The study involved the recruitment of eight refugees who had secured their status in the UK on the basis of being a sexual minority. Interviews took place between March 2018 and February 2020. Participants were primarily recruited through snowball sampling after I had made contact with two initial participants via support groups. The names of these groups have been withheld to protect the anonymity of participants. However, I attended in-person to establish myself as a safe and known person. Attendance at these groups resulted in making contact with the first two participants who wished to take part

12 I would, personally, object to the concept of "genuine" being applied in such circumstances. Nonetheless, it is recognised that practitioners, and those seeking to positively influence policy on the ground, need to operate in a political scenario where such distinctions (between genuine and false) are viewed not only as acceptable, but salient. 
in the study. Lee and Renzetti (1990) have highlighted the effectiveness of engaging with support groups when attempting to investigate sensitive topics. After speaking to me, these participants connected me with others in their friendship networks.

Alongside attending support groups, I also attempted to utilize open calls for participants. I put out calls across the social media sites Twitter and Facebook and placed leaflets across areas where LGBTQ+ people often congregate in London. However, these open calls for participants yielded contact with just one person despite running for almost 2 years. In general, it seemed that refugees were unwilling to consider participating in the study unless they had either met me through support groups or been put in contact with me through a trusted third party.

The reliance on snowball sampling was partly adopted to avoid prejudicing my results through the application of overly selective criteria. Indeed, as Lee and Renzetti (1990, p. 517) have argued, 'sampling decisions can rarely be divorced from theoretical issues, particularly those dealing with how populations are defined'. For example, if I had sought to have a minimum number of lesbian participants, I would have immediately circumscribed the study to look only at people who identify with the currently recognized categories of sexuality/sexual diversity. This, would, of course, have substantially undermined the goals of the research. As such, the only exclusion criteria that were engaged in conducting the study were that participants needed to have successfully claimed asylum in the UK on the basis of their sexual orientation, behavior, or identity. Otherwise put, the only criteria were that participants were, in some sense, a sexual minority. Even this approach to sampling is problematic because it requires participants to have achieved status in the UK. This will only have happened if they were recognized as being a sexual minority by either a Home Office decision-maker or, on appeal, by an immigration judge. As such, the study may have restricted the ability of those who were not recognized to offer potentially relevant perspectives. However, as discussed below, the study also needed to take note of wider risks such as the potential of re-traumatising participants. ${ }^{13}$ Thus, given the need to avoid (re)traumatizing participants, it was decided that a focus on those who had been successful in their asylum claims would be a more ethical approach to conducting the research. In this regard, it is further recognized that some participants may have articulated themselves and their experiences in a manner that they thought would be most intelligible to me and, as such, may have presented their sexual diversities in a manner consistent with the languages and organisations commonly seen in the UK.

Given the status of sexually diverse refugees as potentially traumatized people, ethics played a central role throughout the interview process from recruitment and design to analysis (Cowles 1998). Indeed, as mentioned above, the reason that the study focused on people who had successfully claimed asylum in the UK was primarily to minimize the potential of re-traumatizing participants. Of course, considerations of being able to contact a sufficient sample were also key. Similarly, the employment of a more naturalistic and qualitative approach to interviewing was partially motivated by a desire to avoid recreating the experiences participants may have had when dealing with the Home Office. This approach instead focuses on making the interview a site of reciprocity in which participants are made to feel comfortable to share their feelings (Booth and Booth 1994). Elam and Fenton (2003, pp. 19-20) have argued that semi-structured interviews are the best approach to sensitive topics as the researcher is on hand to take appropriate action if participants become uncomfortable during the interview process. Further, as Murray has argued, this form of interviewing can be therapeutic for refugees, offering them an opportunity to share their experiences with a supportive and understanding interlocutor (Murray 2014).

13 For a discussion of re-traumatisation see Shidlo and Ahola (2013). 
The qualitative approach to interview analysis took the form of an ethnographically informed phenomenological narrative enquiry approach. Phenomenological narrative inquiry interviews seek information on the experiences of participants in order to facilitate a greater understanding of the meanings they attach to such experiences (Hoffding and Martiny 2016; Black et al. 2011; Crouch and McKenzie 2006). This approach seeks to understand the heterogeneity of experiences among sexually diverse asylum seekers by conceptualizing the meaning they attach to their own experiences of sexual orientation, sexual behavior, and sexual identity. The interviews also sought to make sense of how they interpreted and conceptualized the responses of others to their sexual diversity. This phenomenological approach was combined with an ethnographic outlook that sought to situate participant's experiences within their own languages and epistemologies (Roulston and Choi 2018).

The study was undertaken with a qualitative conception of knowledge production. As such, the adequacy of the sample was not assessed on the basis of generalizability. Rather, the work focused on demonstrating the heterogeneity of lived experiences among sexual minority refugees. As Schrier has argued, the validity of qualitative studies should be founded on 'the relationship between our observations and the case in its entirety: how well is the variability within a given instance represented in our observations' as opposed to whether or not a given experience is generalizable to all who share a given identity or experience (Schrier 2018, p. 87). Put another way, when undertaking qualitative interviews, the focus should be on looking for examples of heterogeneity and diversity rather than seeking to find experiences that are shared by all.

Although the study had a small sample, it is comparable with other research undertaken utilizing phenomenological methods. Looking at other qualitative studies that have utilized methods informed by phenomenological narrative analysis, Black et al. drew on a sample of 10 participants when they sought to undertake a study of how victims of child sexual abuse experienced and made sense of legal proceedings. As such, the sample of eight participants is in accordance with other studies that utilized the methods employed. The adequacy of the sample was further assessed through the concept of 'information power' (Malterud et al. 2016). Information power proposes that the adequacy of a sample should be judged with regard to (a) the aims of the study; (b) the specificity of the sample; (c) the use of established theory and literature; (d) the quality of the interview dialogue; and (e) the analysis strategy that is going to be employed. On the basis of these five criteria, it was determined that the eight interview dialogues were sufficient to fulfill the aims of the study and produce relevant and important insights for future research and policy. Across the following sections, I describe how some of the experience's participants shared challenged the ways in which sexualities are commonly conceived.

\section{Lived Realities: The Narratives of Sexually Diverse Refugees}

The preceding sections set out how the 2016 API has-in alignment with a wider shift in how sexuality is conceptualized-promoted forms of evidence that result in decisionmakers seeking narratives of identity development. Despite this, many participants recounted their sexual diversities in terms of behaviours and desires rather than identities. The key themes that came through in the lived experiences of the refugees I spoke to related to identity, or the lack thereof, community, and the forms of evidence that they had been asked to provide by either the Home Office or their own representatives. These themes are complex and interwoven. Due to the interaction of race, gender, and sexuality, they operate on an intersectional terrain. ${ }^{14}$ For example, Abdullah, ${ }^{15}$ an Omani refugee, disputed the idea that his sexuality constituted an identity. Specifically, he told me that:

14 For a discussion of Intersectionality see Crenshaw (1989).

15 All participant names have been changed in order to protect their anonymity. 
I never really identified with my sexuality. I recognized my sexuality. I accepted it. I was okay with it. I even lived with it. But the thing is, here is where it gets more complicated, identity is a very difficult word to identify. In every culture there is a certain set of values associated with identity.

Abdullah went on to tell me about how, within Omani culture, identity was associated with characteristics such as one's faith group, tribe, or nationality. Crucially, he explained how one's sexual attractions or behaviours were not viewed as a fundamental statement or issue regarding who one is. Indeed, he directly addressed the disconnect between his and the Home Office's conception of sexual diversity, telling me that:

[The Home Office's] understanding of homosexuality was that of a gay person. To me, gay is so different than homosexual. I mean homosexual is your sexual attraction, full stop. But when you are gay it is not just your attraction; it is also how you express your attraction, and the slogans which you use to express that attraction, and the way you conduct yourself in relation to that attraction. So, basically, you have to re-culture yourself in accordance with that attraction and if you have not re-cultured yourself yet, then you are not gay yet. You are just homosexual.

As Abdullah identifies, in the UK, sexuality is largely seen as a form of identity. It is understood as something that conditions how you express yourself and as a fundamental element of who you are. Whereas, for him, sexuality constituted an attraction. This is to say that Abdullah called himself homosexual in the sense that he was sexually attracted to men. As Ahmed would put it, his orientation called him towards men as objects of desire (Ahmed 2006). However, he did not view this attraction as making him a particular kind of person, nor did he see his attraction as having any particular implication for how he would express himself. So, while the Home Office expected a narrative of identity, his experiences corresponded more to an orientation. As such, the forms of evidence anticipated in the 2016 API, which focus on how someone is different from the broader society, were ill-fitting for someone who conceptualized themselves as fundamentally the same as those around them apart from simply having an attraction to people of the "same"-sex.

This idea of sexuality as an identity carries with it further corollaries. For example, identity, as argued by Foucault (1998), links directly to ideas of truth. This is to say that, when someone declares their sexuality, it is perceived as revealing a fundamental truth about themselves. As such, it is regarded as being a statement around who someone is that is fixed and stable in nature. This was, for example, clear in the narrative of Masani, a Ugandan refugee, who told me about how her having previously been married to a man was taken as evidence that her claim to be a lesbian was not credible. She told me that:

I was forced to marry. I had no choice. Because if I had refused, then my sexuality would have been suspected. But, when I came here, they said I was not a lesbian because I have been married. The letter made it sound so simple, you had a husband ... Therefore, it is not credible that you are a lesbian.

Here, the idea of fixed identity is clear to see, with previous partners of the opposite sex being viewed as incompatible with the fixed terms in which sexuality is expected to manifest. It is noted that this does not necessarily constitute an argument against identity itself, but rather an argument against fixed conceptions of identity. Nonetheless, given the noted issues bisexual claimants face, the current system appears strongly to expect a stable identity that is monosexual in nature (Rehaag 2009). Such a focus, of course, ignores the extent to which heterosexual marriage is one of the primary strategies that sexually diverse people seeking to hide their sexual diversity from the surrounding society adopt (Giametta 2017, p. 45). However, even more pressingly, it shows how sexuality subsumes sexual orientation and behaviour under part of a wider identity where, even while being a prohibited topic of discussion, sexual behaviour is viewed as a key marker of a "genuine" sexuality. Note should also be taken of the extensive research which has demonstrated the fluid nature of human sexual behaviours and desires (Dustin and Held 2018; Diamond 
2008; Savin-Williams 2006). It should also be noted that Masani's experiences may relate to the specific and intersectional issues she faces as a sexual minority woman. For example, as a woman she may have faced additional pressures to marry within her country of origin when compared to a sexually diverse man in the same situation. Nonetheless, this marriage is then taken as evidence that undermines the credibility of her claim. As such, it shows that sexuality was envisaged, in her dealings with the Home Office, as essentially fixed and unchanging.

Expectations around fixed sexual behaviour are also reinforced by an apparent view that sexuality carries implications for where, and with whom, people will socialize. This is clear on the text of the API, which informs decision-makers that:

To enable claimants to present their case, it may be necessary to ask questions about where claimants have socialized or whether, for example, they have been members of clubs, groups, or organizations, including through social media. Where a claimant has indicated that they have interacted with the LGB community, questions enabling the claimant to detail their knowledge and/or interactions with LGB contacts, groups and activities (in either their country of origin or the UK) may be useful (UK Visas and Immigration 2016, p. 23).

Indeed, all eight respondents said that they had been asked to provide photos of themselves at pride events or attending gay venues. They also recalled being asked to provide evidence that they had engaged in a wider gay life, such as by providing cinema stubs or other evidence to demonstrate dates and engagement with other members of the same sex. These requirements were made clear, for example, in the narrative of Chataluka, an Egyptian refugee, who told me that:

What my solicitor helped me with was that she asked me about certain things that should be in my evidence. For example, I would have to attend pride and take pictures there. Which was the first time ever I had been to pride. I went with my friends; it was a great time. But I was a bit nervous about it ... Also, to go to gay clubs and take pictures as much as you can, out with friends. So, I built up a case properly and I think that we went about it in a very professional way

The expectation to attend particular spaces is founded on a premise of identity. This is because it is representative of an expectation that a certain type of person will attend a given type of space. During the interviews, participants recounted both personal and practical difficulties with providing these forms of identity-driven evidence. Indeed, note should be taken of the "professional" way in which Chataluka notes he approached the gathering of evidence. Singer has also noted the 'Kafkaesque' need to provide objective evidence of being openly sexually diverse (Singer 2021, p. 256). As this suggests, the current process was viewed as something akin to work, a process of generation, rather than simply providing evidence. Further, Abeo, a Nigerian refugee, told me about how living in shared Home Office accommodation had made it impossible for him to demonstrate the forms of evidence expected by the Home Office. He recounted that:

I was taken to this apartment in Middlesbrough ... I was staying with three other people. And that was also a big thing for me, because I don't know these people, So I don't know how much of my sexuality I can bring. So, I had to go back into the closet, because they would bring their girlfriends, or they would bring their friends and I can't do that. As much as I would love to hang out with them and have drinks, I can't because once the conversation had come up, "oh you don't bring girls are you gay?" So that became like a tough thing for me, so I would spend a lot of time in my room.

While this point does not directly cut across the identity-driven manner in which sexuality is conceived, it does problematize the expectations that an identity-driven conception of sexuality results in. Specifically, Abeo's narrative draws attention to how conceiving of "sexuality" as an identity leads to asylum claims being assessed in terms of the claimant's ability to demonstrate their conformity with "westernized" norms such as visibility, indi- 
vidualism, and consumerism (See Further: Dos Ventos Lopes Heimer 2020; Jordan 2009; Millbank 2009).

Going beyond the practical issues that arise when sexuality is conceived as indicating who one will socialize with, and the spaces they may attend, it is also important to consider how the expectations of decision-makers regarding these issues may simply not align with the ways in which claimants understand their own sexual diversities. As Millbank has argued, there will be some claimants that are simply 'homebodies' who lack any particular desire to engage in nightlife and the, often highly alcohol-driven and sexually charged, spaces in which sexually diverse people in the UK congregate (Millbank 2009, p. 19). Indeed, the problematic way in which "sexuality" is viewed as leading one to be a certain type of person is manifest in the-well meaning-exaltation of Lord Rodger in HJ and HT that:

In short, what is protected is the applicant's right to live freely and openly as a gay man. That involves a wide spectrum of conduct, going well beyond conduct designed to attract sexual partners and maintain relationships with them. To illustrate the point with trivial stereotypes from British Society: Just as male heterosexuals are free to enjoy themselves playing rugby, drinking beer and talking about girls with their mates, so male homosexuals are to be free to enjoy themselves going to Kylie concerts, drinking exotically coloured cocktails and talking about boys with their straight female mates. [78]

While Lord Rodger is right that such stereotypes are generally trivial and will often be harmless, this judicial articulation, taken alongside the sections of the API already explored in this article, express a sort of emblematic knowledge of sexuality. This emblematic knowledge of "sexuality" sees it predominantly as an identity. This kind of ordinary knowledge is, as Berlant has argued, informative due to 'its very popularity or its effects on everyday life ... [it] requires reflection on what is merely undramatically explicit' (Berlant 1998, p. 119). As such, it is argued that these stereotypes, as well as the expectations for social engagement present within the API, are representative of an ordinary or emblematic conception of sexuality as identity. As Dawson and Gerber have argued, these expectations 'result in lesbian, gay, and bisexual asylum seekers needing to visibly demonstrate their identity, as a form of proof, in a way that other asylum seekers do not' (Dawson and Gerber 2017, p. 298). Indeed, as Juss has noted:

The suggestions ... [of Lord Rodger] ... were always self-indulgent and unlikely to bear much resemblance to the realities of everyday life for many in the world today, if only because a gay asylum seeker from Africa was not going to be found "drinking exotically coloured cocktails" in the bars of Kampala, Kano or Kiribati, if he had spent his time dodging persecution from state authorities. The judgement serves to typify the conceptualization today of refugee rights as bourgeoise rights. (Juss 2015, p. 134)

Participants also noted the issues around expecting evidence of socializing and community engagement as a means through which to demonstrate one's sexuality. Here the expectation on Asylum Seekers can be seen regarding their conduct both in the country of origin (the API notes that such engagement might be via means such as social media) and within the UK (See UK Visas and Immigration 2016). For example, Masani told me about how:

I can understand how here, or in places where you are protected, people might want to create an identity around what they do. But to assume that just because someone is fleeing a country due to their sexual interest, this must be an identity that means all these different things is just wrong. 
Indeed, even those claimants who felt that their sexuality was something that they had been born into disputed the idea that a focus on social engagements was a useful way of determining whether a given claimant's sexuality was to be believed. For example, Abeo told me:

I think there is a universality of identity, that gay men are always in love with other men and gay women are always in love with other women. So that is a universality of identity. Now, how we then socially express it depends on the environment where we find ourselves.

This suggests that, while Abeo described his experiences of being gay as universal, in that he felt all gay people experience attraction to members of the same-sex, he recognized that the ways in which this attraction might be expressed, and thus the behaviours that people might engage in, would be contingent on the situations in which they find themselves. Indeed, he went on to tell me that:

If you ask me, do I go to gay parties, and I say yes there are gay parties. And [then] you say do I go, and I say no I don't go to gay parties, and you say, "oh so you are not gay", that is a disservice. Because you can say oh people here go to gay clubs. But people here go to gay clubs because there is a freedom to do so.

Other participants cited their ability to demonstrate clear examples of social and romantic engagements in a visible and open way as being key to the success of their claims. For example, Abasi, an Egyptian refugee, told me about how he had needed to use 'photos of going to clubs and going to pride ... just to support my statements'. While Chataluka told me about how he was helped by being a, 'Person who keeps a lot of data ... it was just all left from my relationships or my private life. So, when I used to chat with people, I used to save a copy of the chats and have them on my external hard drive. Photos too, photos of my ex-boyfriends'.

Drawing this all together, it can be seen that the expectations of the Home Office appear to coalesce around a series of differences in the narratives of sexually diverse refugees and asylum seekers that effectively express how they have come to develop identities that mark them out as being different from the surrounding society, as being a particular kind of person who has a fixed identity that conditions who they are and who they socialize with.

\section{Conceptual Space: A Turn to Sexual Diversity}

As the above evidence suggests, sexuality has increasingly come to be viewed through the lens of identity. While this may have been tactically useful during the development and expansion of rights for most sexual and gender minorities, or at least those sexual and gender minorities who were born and live in the UK, it is important to recognize that all tactical decisions come with trade-offs. Indeed, as Rubin has argued, 'it is an exercise in futility to anoint any particular critical stance or political movement with permanent transgressive or revolutionary status' (Rubin 2010, pp. 369-70). Therefore, it is argued that identity now occupies too much of the conceptual space around "sexuality", with the result being that the emblematic example of sexuality is figured as a fixed and stable identity. Within the context of the asylum system, this can lead to difficulties for asylum claimants who come from cultures in which heterogenous sexual desires and behaviours are not conceived of in such a manner. Indeed, I have argued that despite the effort to construct the 2016 API in neutral terms that leave space for "non-western" conceptions of sexual diversity, the presumption that sexuality is an identity results in expectations of an ultimately fixed status that is viewed as a fundamental "truth" about oneself, which all of us are thought to "discover" over time.

Given that sexuality has become deeply implicated as an identity, it is suggested that we need to develop new conceptual frameworks in order to generate critical space to recognize the shortcomings and trade-offs associated with how we make sense of sexual difference. Therefore, I propose that shifting our understanding of sexual difference 
from sexuality to a framework of sexual diversity can provide greater conceptual space within which to recognize the heterogenous range of ways in which sexual and gendered behaviours, identities, and desires are experienced and embodied.

The term sexual diversity 'capture[s] anyone who engages in sexual activity with, is attracted to, or who identifies with, a culture founded around a non-normative sexual practice or partner' (Powell 2021, p. 53). It is recognized that this is a very broad definition which captures a wide range of people. The term captures those who hold a lesbian or gay identity in a contemporary "western" style. However, it would also be capable of capturing those who understand themselves without reference to sex, or those who simply view their sexual activities as a behaviour, as opposed to something which makes them a particular type of person (see Morris 2021a).

It is arguable that adopting a conception of sexual diversity may mean that those who participate in practices such as BDSM, alongside other sexually marginalized groups, might be included alongside those who hold a sexuality in the terms we commonly understand it. However, when suggesting a conceptual framework for an issue such as asylum, which has potential life and death implications for claimants, it is better to be over rather than under-inclusive in our deployments.

It should also be noted that the relationship between sexual diversity and sexual behavior or sexual attraction is complex. In essence, sexual diversity directly captures sexual behavior and sexual orientation (as defined in Section 2). This is because, like sexuality, sexual diversity is intended to be an umbrella term that embraces the different behaviors, orientations, and identities through which people live and experience sex. Thus, the term subsumes both sexual behavior and sexual orientation alongside sexual identity. Its relationship to sexual behaviour and orientation is thus as an overarching concept that brings the two together, rather than as a proposed alternative. Although, it is certainly hoped that this more circumspect framing may avoid some of the problematic oversexualization that Juss noted occurring prior to the $A, B$, and $C$ decision (Juss 2015).

The purpose in proposing a new framework for making sense of sexual differences is twofold. First, shifting away from the framework of sexuality would help to discourage the forms of ordinary and emblematic knowledge decision-makers deploy when faced with the term sexuality. Second, it is argued that a framework of sexual diversity creates space to recognize the potential for policies to be LGBT+ inclusive while continuing to exclude some sexually diverse people. For example, Puar has raised critiques over how, at the international level, certain enactments of pro-LGBT+ rights discourse combine with forms of nationalism to construct what she terms 'homonationalism' (Puar 2006, 2012). Homonationalism describes 'arrangements of sexual exceptionalism ... that complicates the dichotomous casing away of the nation as only supportive and productive of heteronormativity and disallowing of homosexuality' (Puar 2006, p. 68). Homonationalism has been used to justify and legitimize the use of violence and the practice of othering some "non-western" states. And, as Murray points out, can also see asylum claimants being expected to disclaim and criticize their countries of nationality in order to be viewed as credible (Murray 2014). As such, it is argued that the framework of sexual diversity can be useful for drawing attention to the ways in which certain pro-LGBT+ policies do not take account of intersectional or culturally specific manifestations of sexual difference. Sexual diversity can be useful in pushing back against these tendencies and instead creating conceptual space to support and advocate for rights and support for a wider range of sexually and gender different people at a global level, without recreating colonial dynamics or enforcing conformity to "westernized" social scrips.

Within the asylum context, sexual diversity would operate in a relatively similar way to the current focus on sexuality. It would provide a form of Particular Social Group to which those fleeing persecution could claim membership. That Particular Social Group could be defined as being 'sexually diverse people'. Such a group would be capable of better capturing the heterogeneity of sexual difference that might be encountered. Importantly, this framing of a Particular Social Group would help separate the ways in which asylum 
claimants are understood from the everyday representations of sexuality that decisionmakers might encounter in their day to day lives in the UK. Of course, a shift towards sexual diversity would also require a re-writing of the 2016 API to produce a set of guidance that is more readily attuned to the lived experiences of sexually diverse refugees and asylum seekers. As such, I do not claim, by any means, that shifting to sexual diversity would be a panacea that would solve all of the issues that arise in the asylum claims of sexually diverse people. However, I argue that such a conceptual shift could make greater space for the true heterogeneity of sexual difference to be institutionally recognized and given the protection and fostering promised by the Refugee Convention.

\section{Conclusions}

This article has argued that sexuality has increasingly come to be viewed as a fixed and stable identity. As I have demonstrated, however, this identity-driven way of conceiving of sexuality is not always aligned to the heterogenous ways in which sexually diverse refugees and asylum seekers conceptualize their own sexual diversities. Therefore, the article calls for a linguistic and conceptual shift to a framework of sexual diversity. It is argued that such a shift would help to create greater conceptual space for a wider range of sexual and gender differences to be recognized and offered appropriate protection under the Refugee Convention.

While it is acknowledged that changes to language and concepts alone will not remedy the injustices and harms perpetuated by poor asylum decision-making, current attempts to remedy these issues start from poor foundations when they uncritically advance the idea of sexuality as an identity. This is because constructing a policy that calls for a focus on a narrative of difference leads to decision-makers seeking forms of difference that are aligned with the ordinary and emblematic examples of sexual difference they commonly see in the UK. As such, what was initially intended as a set of helpful topics for decision-makers ultimately solidifies into a relatively fixed and determinate expectation of a narrative of identity development. Therefore, it is argued that changes need to be made at the conceptual level to provide the best opportunity for future policy and practice improvements to succeed in creating a system that is better able to recognize the heterogenous ways in which sexual diversity presents at the global level.

Funding: The research was not funded by any external body. However, some of the arguments in this paper were developed in the author's unpublished PhD thesis. The PhD research was supported by a City, University of London Doctoral studentship between September 2017 and September 2020.

Institutional Review Board Statement: The study was conducted according to the guidelines of the Declaration of Helsinki, and approved by the City Law School Research Ethics Committee at City, University of London. It was granted approval on 23rd September 2018 under Application ID: ETH1819-0040.

Informed Consent Statement: Informed consent was obtained from all subjects involved in the study.

Data Availability Statement: Data used in this study are not publicly available. This is due to the sensitive nature of the data gathered, the need to protect participant anonymity, and the absence of participant consent to data being publicly available during the data collection process.

Acknowledgments: Thanks are due to Max Morris for support and many intellectually stimulating conversations during the drafting of this paper. I would also like to thank the anonymous reviewers who offered generous feedback that has made this paper immeasurably stronger. Finally, thanks are due to the guest editors of the special issue-Aleardo Zanghellini and Kate Gleeson-for their support and insightful feedback on earlier versions of the paper. All mistakes, of course, remain entirely my own.

Conflicts of Interest: The author declares no conflict of interest. 


\section{References}

Adler, Libby. 2018. Gay Priori: A Queer Critical Legal Studies Approach to Law Reform. Durham: Duke University Press.

Ahmed, Sarah. 2006. Queer Phenomenology: Orientations, Objects, Others. Durham and London: Duke University Press.

Ashford, Chris, Max Morris, and Alex Powell. 2020. Bareback sex in the age of Preventative Medication: Rethinking the "Harms" of HIV Transmission. Journal of Criminal Law 84: 596-614. [CrossRef]

Bennett, Claire. 2014. Lesbians and United Kingdom Asylum Law: Evidence and Existence. In Gender in Refugee Law: From Margins to Centre. Edited by Arbel Efrat, Dauvergne Catherine and Milllbank Jenni. London: Routledge.

Berlant, Laurent. 1998. Collegiality, Crisis and Cultural Studies. Profession, 105-16.

Bernstein, Mary. 2005. Identity Politics. Annual Review of Sociology 37: 47-74. [CrossRef]

Black, Christina, Per A. Gustafsson, IngBeth Larsson, and Carina Bertero. 2011. Managing the Legal Proceedings: An Interpretive Phenomenological Analysis of Sexually Abused Children's Experience with the Legal Process. Child Abuse E Neglect 35: 50-57.

Booth, Tony, and Wendy Booth. 1994. The Use of Depth Interviewing with Vulnerable Subjects: Lessons from a Research Study of Participants with Learning Difficulties. Social Science and Medicine 39: 415-24. [CrossRef]

Bruce-Jones, Eddie. 2015. Death Zones, Comfort Zones: Queering the Refugee Question. International Journal of Minority and Group Rights 22: 101-27. [CrossRef]

Chelvan, S. 2011. Put Your Hands Up (If you Feel Love). Immigration, Asylum and Nationality Law 25: 56.

Chelvan, S. 2020. The Emotional Journey and the DSSH Model: A Positive Tool for Credibility Assessment. Paper presented at the SOGICA Conference, online, July 7-9.

Cowles, Kathleen. 1998. Issues in Qualitative Research on sensitive Topics. Western Journal of Nursing Research 10: 163-79. [CrossRef]

Crenshaw, Kimberlé. 1989. Demarginalizing the Intersection of Race and Sex: A Black Feminist Critique of Antidiscrimination Doctrine, Feminist Theory and Anti-Racist Politics. University of Chicago Legal Forum 1: 139-67.

Crouch, Mira, and Heather McKenzie. 2006. The Logic of small Samples in Interview-Based Qualitative Research. Social Science Information 45: 483-99. [CrossRef]

Dawson, Jasmine, and Paula Gerber. 2017. Assessing the Refugee Claims of LGBTI People: Is the DSSH Model Useful for Determining Claims by Women for Asylum Based on Sexual Orientation. International Journal of Refugee Law 29: 292-322. [CrossRef]

Diamond, Lisa. 2008. Sexual Fluidity: Understanding Women's Love and Desire. Cambridge and London: Harvard University Press.

Dos Ventos Lopes Heimer, Rosa. 2020. Homonationalist/Orientalist Negotiations: The UK Approach to Queer Asylum Claims. Sexuality and Culture 24: 174-96. [CrossRef]

Dustin, Moira. 2018. Many Rivers to cross: The Recognition of LGBTQI Asylum in the UK. International Journal of Refugee Law 1: 104-27. [CrossRef]

Dustin, Moira, and Nina Held. 2018. In or Out? A Queer Intersectional Approach to "Particular Social Group" Membership and Credibility in SOGI Asylum Claims in Germany and the UK. Genius 2: 74-87.

Elam, Gillian, and Kevin Fenton. 2003. Researching Sensitive Issues and Ethnicity: Lessons from Sexual Health. Ethnicity and Health 8: 15-27. [CrossRef] [PubMed]

Foucault, Michel. 1970. The Order of Things: An Archeology of the Human Sciences. London: Tavistock.

Foucault, Michel. 1998. The History of Sexuality: The Will to Knowledge. Translated by Robert Hurley. London: Penguin.

Giametta, Calogero. 2017. The Sexual Politics of Asylum: Sexual Orientation and Gender Identity in the UK Asylum System. London: Routledge.

Giametta, Calogero. 2020. New Asylum Protection Categories and Elusive Filtering Devices: The Case of "Queer Asylum" in the UK and France. Journal of Ethnic and Migration Studies 46: 142-57.

Halberstam, Jack. 1998. Female Masculinity. Durham: Duke University Press.

Hall, Stuart. 1994. Some "Politically Incorrect" Pathways through PC. In The War of the Words. Edited by Sarah Dunant. London: Virago.

Hanna, Fadi. 2005. Punishing Masculinity in Gay Asylum Claims. The Yale Law Journal 114: 913-20.

Hathaway, James. 1998. The Law of Refugee Status. New York: Butterworths.

Hathaway, James. 2005. The Rights of Refugees under International Law. Cambridge: Cambridge University Press.

Hoffding, Simon, and Kristian Martiny. 2016. Framing a Phenomenological Interview: What, Why and How. Phenomenological Cognitive Science 15: 539-64. [CrossRef]

Honkala, Nora. 2017. She, of course, Holds no Political Opinions: Gendered Political Opinion Ground in Women's Forced Marriage Asylum Claims. Social and Legal Studies 26: 166-87. [CrossRef]

Johnston, Tim. 2015. Beyond "Born This Way". PhiloSPHOHIA 5: 140-44.

Jordan, Sharalyn. 2009. Un/Conventional Refugees: Contextualising the Accounts of Refugees Facing Homophobic or Transphobic Persecution. Refuge 26: 165-82. [CrossRef]

Juss, Satvinder. 2015. Sexual Orientation and the Sexualisation of Refugee law. International Journal on Minority and Group Rights 22: 128-53. [CrossRef]

Khan, Tawseef. 2016. Investigating the British Asylum System for Lesbian, Gay and Bisexual Asylum Seekers: Theoretical and Empirical perspectives on Fairness. Liverpool: University of Liverpool. 
Khan, Tawseef. 2019. Sexual Orientation and Refugee Law: How Do Legal Sanctions Criminalizing Homosexuality Engage the Definition of Persecution. In Research Handbook on International Refugee Law. Edited by Juss Satvinder. Cheltenham: Edward Elgar.

Lee, Raymon, and Claire Renzetti. 1990. The Problem of Researching Sensitive Topics: An Overview and Introduction. American Behavioral Scientist 33: 510-28. [CrossRef]

Lewis, Rachel. 2014. "Gay? Prove it": The Politics of Queer Anti-Deportation Activism. Sexualities 17: 958-75. [CrossRef]

Malagodi, Mara, and Alex Powell. 2019. A Rose by Any Other Name Would Smell as Sweet: Third Gender and Constitutional Identity in Nepal. Paper presented at the 8th Asian Constitutional Law Forum, Hanoi, Vietnam, December 6-7.

Malterud, Kirsti, Volkert Dirk Siersma, and Ann Dorrit Guassora. 2016. Sample Size in Qualitative Interview Studies: Guided by Information Power. Qualitative Health Research 26: 1753-60. [CrossRef] [PubMed]

Massad, Joseph. 2002. Re-Orenting Desire: The Gay International and the Arab World. Public Culture 14: 361-85. [CrossRef]

Millbank, Jenni. 2009. "The Ring of Truth": A Case Study of Credibility Assessment in Particular Social Group Refugee Determinations. International Journal of Refugee Law 21: 1-33. [CrossRef]

Morris, Max. 2021a. The Limits of Labelling: Incidental Sex Work Among Gay, Bisexual, and Queer Young Men on Social Media. Sexuality Research and Social Policy, 1-14. [CrossRef]

Morris, Max. 2021b. The Politics of Testing Positive: An Autoethnography of Media (Mis)representations at the 'Start' and 'End' of Different Pandemics. Culture, Health and Sexuality 23: 1485-99. [CrossRef]

Murray, David. 2014. Real Queer: "Authentic" LGBT Refugee Claimants and Homonationalism in the Canadian Refugee System. Anthropologica 56: 21-32.

Norton, Rictor. 2010. F* ck Foucault. Or how eighteenth-century homosexual history validates the essentialist model. Paper presented at UCLA Mellon Sawyer Seminar Homosexualities, Los Angeles, CA, USA, May 27. Available online: https: / www.academia.edu/ 5938080/F_ck_Foucault_or_How_18th_century_homosexual_history_validates_the_essentialist_model (accessed on 2 September 2021).

Phelan, Shane. 2000. Queer Liberalism. The American Political Science Review 94: 431-42. [CrossRef]

Powell, Alex. 2020. Normative Understandings: Sexual identity, Stereotypes, and Asylum Seeking. In The Research Handbook on Gender, Sexuality, and Law. Edited by Ashford Chris and Maine Alexander. Cheltenham: Edward Elgar.

Powell, Alex. 2021. Queering Refugee Law: A Study of Sexual Diversity in Asylum Policy and Practice in the United Kingdom. London: University of London.

Powell, Alex, and Mara Malagodi. 2021. A Rose by Any Other Name Would Smell as Sweet: Third Gender and Constitutional Identity. Paper presented at the Socio-Legal Studies Association, Cardiff University, online, March 30-April 1.

Puar, Jasbir. 2006. Mapping US Homonormativites. Gender, Place and Culture 13: 67-88. [CrossRef]

Puar, Jasbir. 2012. Terrorist Assemblages: Homonatonalism in Queer Times. Durham: Duke University Press.

Rehaag, Sean. 2009. Bisexuals Need Not Apply: A Comparative Appraisal of Refugee Law and Policy in Canada, the United States, and Australia. The International Journal of Human Rights 13: 415-36. [CrossRef]

Roulston, Kathryn, and Myungweon Choi. 2018. Qualitative Interviews. In The Sage Handbook of Qualitative Data Collection. Edited by Flick Uwe. London: Sage Publications.

Rubin, Gayle. 2010. A Little Humility. In Gay Shame. Edited by Halperin David and Traub Valerie. Chicago: University of Chicago Press.

Rubin, Gayle, and Judith Butler. 1994. 'Sexual Traffic'. Differences: A Journal of Feminist Cultural Studies 6: 62-99.

Rumbach, Jennifer. 2015. Module 02: Conducting Interviews. United Nations High Commissioner for Refugees. Available online: https://lgbti.iom.int/sites/default/files/Module\%202\%20Conducting\%20interviews/Module\%2002_Participant\%20 Workbook_Nov2016.pdf (accessed on 7 September 2021).

Savin-Williams, Rich. 2005. The New Gay Teenager. New York and London: Harvard University Press.

Savin-Williams, Rich. 2006. Who's Gay? Does it Matter? Current Directions in Psychological Science 15: 40-44.

Savin-Williams, Rich. 2017. Mostly Straight: Sexual Fluidity among Men. Cambridge and London: Harvard University Press.

Schrier, Margrit. 2018. Sampling and Generalization. In The Sage Handbook of Qualitative Data Collection. Edited by Uwe Flick. London: Sage Publications.

Sedgwick, Eve Kosofsky. 2008. The Epistemology of the Closet, 2nd ed. California: University of California Press.

Shidlo, Ariel, and Joanne Ahola. 2013. Mental Health Challenges of LGBT Forced Migrants. Forced Migration Review $42:$ 9-11.

Singer, Sarah. 2021. "How much of a Lesbian Are you?" Experiences of LGBT Asylum Seekers in Immigration Detention in the UK. In Queer Migration and Asylum in Europe. Edited by Mole Richard. London: UCL Press.

Spijkerboer, Thomas. 2013. Sexual Identity, Normativity and Asylum. In Fleeing Homophobia: Sexual Orientation, Gender Identity and Asylum. Edited by Spijkerboer Thomas. Oxford: Routledge.

Spivak, Gayatri. 1985. Criticism, Feminism and the Institution. Thesis Eleven 1: 175-87.

Stonewall. 2007. Some People Are Gay: Get over It. Available online: https:/ /www.stonewall.org.uk/our-work/campaigns/get-overit (accessed on 20 August 2021).

Stychin, Carl. 2014. Being Gay. Government E Opposition 40: 90-109.

Sullivan, Andrew. 1995. Virtually Normal: An Argument about Homosexuality. London: Picador. 
UK Visas and Immigration. 2015. Asylum Policy Instruction: Assessing Credibility and Refugee Status. Home Office. Available online: https://assets.publishing.service.gov.uk/government/uploads/system/uploads/attachment_data/file/397778 /ASSESSING_CREDIBILITY_AND_REFUGEE_STATUS_V9_0.pdf (accessed on 19 November 2021).

UK Visas and Immigration. 2016. Asylum Policy Instruction: Sexual Orientation in Asylum Claims. Home Office. Available online: https://assets.publishing.service.gov.uk/government/uploads/system/uploads/attachment_data/file/543882/Sexualorientation-in-asylum-claims-v6.pdf (accessed on 20 August 2021).

UK Lesbian and Gay Immigration Group (UKLGIG). 2013. Missing the Mark: Decision Making on Lesbian, Gay (Bisexual, Trans and Intersex) Asylum Claims. Unison. Available online: https:/ / www.rainbowmigration.org.uk/sites/default/files/2021-03/ Missing-the-Mark-Oct-13_0.pdf (accessed on 7 September 2021).

UK Lesbian and Gay Immigration Group (UKLGIG). 2018. Still Falling Short: The Standard of Home Office Decision-Making in Asylum Claims Based on Sexual Orientation and Gender Identity. Available online: https:/ /www.rainbowmigration.org.uk/ sites/default/files/2021-03/Still-Falling-Short-Jul-18_0.pdf (accessed on 7 September 2021).

Weeks, Jeffery. 2015. 'Beyond the Categories'. Archive of Sexual Behaviour 4: 1901-7. [CrossRef] [PubMed] 